\title{
Enhancing PEM water electrolysis efficiency by reducing the extent of Ti gas diffusion layer passivation
}

\author{
T. Bystron ${ }^{1 *}$, M. Vesely², M. Paidar ${ }^{1}$, G. Papakonstantinou ${ }^{3}$, K. Sundmacher ${ }^{3,4}$, B. Bensmann ${ }^{5}$, R. Hanke- \\ Rauschenbach $^{5}$, K. Bouzek ${ }^{1}$ \\ ${ }^{1}$ Department of Inorganic Technology, University of Chemistry and Technology Prague, Technicka 5, Prague 6, \\ 166 28, Czech Republic. \\ ${ }^{2}$ Department of Organic Technology, University of Chemistry and Technology Prague, Technicka 5, Prague 6, \\ 166 28, Czech Republic.
}

${ }^{3}$ Max Planck Institute for Dynamics of Complex Technical Systems, Department Process Systems Engineering, Sandtorstr.1, D-39106 Magdeburg, Germany

${ }^{4}$ Otto-von-Guericke- University Magdeburg, Department Process Systems Engineering, Universitätsplatz 2, D39106 Magdeburg, Germany

${ }^{5}$ Gottfried Wilhelm Leibniz Universität Hannover, Welfengarten 1, 30167 Hannover, Germany

* Corresponding author, tel.: +420220444272

* Corresponding author, email: bystront@vscht.cz

\begin{abstract}
Proton exchange membrane water electrolysis (PEM WE) suffers from several issues, such as the high cost and low stability of the electrolyser unit components. This is especially pronounced evident for an anode polarised to a high potential and in contact with an acidic membrane. Such a combination is detrimental to the vast majority of electron-conducting materials. Nowadays Ti (possessing a protective passive layer on its surface) is used as the construction material of an anode gas diffusion layer. Since the passivation layer itself is non-/semiconducting, an excessive degree of passivation leads to high surface contact resistance and to energy losses during PEM WE operation. This problem is usually solved by coating the Ti surface with precious metals. This leads to a further increase of the already very high cell investment costs. In this work an alternative method based on appropriate Ti etching (in acid) is presented. The (surface) composition of the samples treated was investigated using SEM, X-ray fluorescence and diffraction and photoelectron spectroscopy. $\mathrm{TiH}_{\mathrm{x}}$ was found in the subsurface layer. This was responsible for preventing excessive passivation of the Ti metal. The superior performance of the etched Ti gas diffusion layer (compared to non-etched) in a PEM water electrolyser was confirmed during an (>100 hour) experiment with current densities of up to $1 \mathrm{~A} \mathrm{~cm}^{-2}$. Using the described treatment the surface contact resistance was substantially reduced and its increase during PEM WE operation was largely suppressed. As this method is very simple and cheap, it has tremendous potential for improving PEM WE process efficiency.
\end{abstract}

\section{Keywords}

PEM water electrolysis, titanium passivation, titanium hydride, photoelectron spectroscopy, surface contact resistance, etching.

\section{Introduction}


Water electrolysis with a proton exchange membrane (PEM WE) is an industrially and energetically interesting process, particularly due to its high intensity, flexibility and efficiency [1,2]. On account of these properties it is an important part of the hydrogen economy scheme [3, 4]. However, PEM WE suffers from several issues, such as the high investment cost of the electrolyser unit and stability. Practically all PEM WE problems are related to the limited stability of the material and the high cost of the construction materials. This is especially pronounced on the anode side of the cell where the anode is polarised to a high potential and is in contact with an acidic (usually Nafion ${ }^{\circledR}$-type) membrane [1]. Such a combination is detrimental to the vast majority of electronconducting materials which, under such conditions, are oxidised and consequently dissolved [5,6]. For this reason, despite tremendous efforts by researchers in recent decades, practically the only useful type of anode catalyst material is based on Ir(oxide) which possesses both sufficient activity and stability. For the same reason, only a limited number of metals can be used for the construction of other anode components (e.g. gas diffusion layer, bipolar plates) [5]. The most common is Ti (and Ta), a representative of "valve" metals which are characterised by a high degree of thermodynamic instability due to which, in the presence of a source of oxygen such as $\mathrm{O}_{2}$ or $\mathrm{H}_{2} \mathrm{O}$, their whole surface is covered by a passivation oxide (hydroxide) layer. This passivation layer, on the other hand, is very stable, adherent and highly compact and it effectively protects the metal from further oxidation. As a result, the actual corrosion resistance of the valve metals (even in rather corrosive environments) is very high [7]. This, together with excellent mechanical properties, low density and biocompatibility, makes Ti (and its alloys) an indispensable material in many highly valued fields such as aerospace, the chemical industry or (bio)medicine $[8,9]$.

As mentioned above, the excellent stability of Ti makes it a state-of-art construction material for several anode components in the PEM water electrolyser. The presence of a passivation layer, however, also has a negative effect on the surface contact resistance since the passivation layer itself is non-/semiconducting. The resistance in the film depends on its thickness as well as on its composition. The thickness of a Ti passivation layer can vary from 2-3 nm (naturally formed under ambient conditions) to tens or even hundreds of nm [10]. Of course, the ohmic contact resistance increases with the thickness of the passivation layer. The effect of the composition of the passivation layer on its resistivity was discussed, for example, in [11]. Passive layer is generally said to be formed by $\mathrm{TiO}_{2}$ (insulator). However, usually only near the top of the passivation film is the ratio O:Ti $=2$ (not considering weakly bound or adsorbed $\mathrm{O}$ species as will be shown later). In its bulk, the passive layer contains sub- and non-stoichiometric oxides $(\mathrm{O}: \mathrm{Ti}<2)$ and acts as a n-type semiconductor [12]. In other words, the oxygen content as well as the average oxidation state of Ti decreases in the direction towards the metal phase. It is only the layer of actual anhydrous $\mathrm{TiO}_{2}$ that functions as passivation protection. Thus, the rising thickness of the passivation layer does not necessarily help to improve its corrosion resistance [10]. The ultimate result of excessive passivation layer formation (and increased surface contact resistance) in the PEM water electrolyser is the loss of energy efficiency. This becomes especially pronounced during intensive operation when current density can approach units of $\mathrm{A} \mathrm{cm}^{-2}$. Under these conditions, energy losses due to ohmic resistance in the system dominate [13]. A common way to solve the problem of excessive Ti passivation is to use the appropriate surface treatment which commonly involves coating Ti with protective layer of precious metal (usually Pt). This, of course, further increases the already very high investment costs of the device and the dependence of the PEM WE technology on precious metals. The surface treatment can be carried out by several methods. Precious metal ion implantation by magnetron sputtering [14] has, for example, been reported. Alternatively, alloying Ti with precious metal (even at the level of about $0.05 \%$ ) has been shown to greatly improve $\mathrm{Ti}$ corrosion resistance [15]. Finally, the same procedure of Ti surface coating by precious metals as that used in dimensionally stable anode (DSA) technology (known since the 1950s and perfected for chlor-alkali industrial applications in the 1960s) can be applied [16]. Although the approach has been successful in DSA production there is a big difference between the precious metal consumption when coating a more or less flat DSA and a porous gas diffusion layer (GDL) for the PEM water electrolyser. It is fair to say that, in the PEM WE literature, problems related to the excessive passivation of Ti components are generally (almost intentionally) ignored.

At this point it is worth taking a more detailed look at how the Ti passivation issue is handled in DSA technology. The general procedure of DSA preparation has been described elsewhere [17]. It usually involves mechanical treatment of the surface, such as sandblasting, followed by chemical etching, several coating steps and final thermal treatment. One of the most crucial steps seems to be the chemical etching. Its purpose is to 
roughen the surface and remove the existing passivation layer. Ideally, titanium hydride is supposed to remain on the surface as it should protect the underlying Ti metal for a few hours] [16]. The etching can, in principle, be performed in various acids. The behaviour of $\mathrm{Ti}$ in aqueous acid solutions has, for decades, been studied by numerous authors, cf. [18-25]. The Ti behaviour is governed by the stability of the passive layer under the given conditions. In general, the rate of Ti dissolution increases with both the rising acid concentration and the solution temperature [26]. The etching process can also be strongly influenced by varying the electrode potential. Basically in all environments, galvanostatic anodic polarisation of the Ti electrode leads to (re)passivation of the surface with the passivation potential being dependent on the electrolyte composition. The properties of the passivation layer, such as thickness, depend largely on the current density/electrode potential applied, the electrolyte composition and, of course, the duration of the polarisation [21]. The stability of the oxide layer is greatly reduced by the presence of fluorides in an acidic environment [24], in fact hydrofluoric acid is practically the only acid that dissolves Ti even in diluted solutions [26, 27]. The rate of Ti dissolution in halogen hydride acid decreases with increasing atomic mass of the halogen [26].

Active metal dissolution is often connected with the absorption of atomic hydrogen in the Ti metal. When the concentration of hydrogen in the metal exceeds the solubility limit under the given conditions, Ti hydrides are formed. It has been reported that the rate/extent of hydride phase formation strongly depends on the exact metal composition, type of phase present, treatment of metal during its production and shaping, rate of diffusion of hydrogen in/through the passive layer (which itself is largely dependent on $\mathrm{TiO}_{2}$ crystal lattice orientation [28]), hydrogen partial pressure and temperature [29]. Covington [30] summarised the three conditions which must exist simultaneously in order for serious hydriding to take place:

- $\quad$ pH either low $(<3)$ or high $(>12)$;

- temperature above $80^{\circ} \mathrm{C}$, otherwise only surface hydrides will be formed;

- hydrogen present/generated in the system.

The first condition seems to be related to the fact that the passivation layer is very stable at medium $\mathrm{pH}$ values and its presence effectively prevents transport of molecular hydrogen towards the Ti [31] and most likely also its dissociation to atomic form [32]. The second condition is given by a very low hydrogen diffusion coefficient in $\mathrm{Ti}$ at low temperatures [33]. The thickness of the hydride layer increases with the duration of exposition to hydriding conditions, temperature and cathodic current density (upon polarisation in the active dissolution region) and can attain several tens of micrometres [34, 35]. An excessive hydridation of Ti leads to its embrittlement [36]. Titanium hydrides are a group of binary metallic compounds with a maximum ratio of $\mathrm{H} / \mathrm{Ti}=2$. Their thermal dehydrogenation starts far above $400{ }^{\circ} \mathrm{C}$ [37]. Their oxidation in air proceeds in several steps starting at about $500{ }^{\circ} \mathrm{C}$ [38]. Interestingly, many properties of the Ti hydrides, such as electron or thermal conductivity, are fairly similar to those of Ti [39].

Based on the above information, it seems that the Ti hydride layer possesses reasonable thermal and chemical stability, offering Ti metal a certain protection against oxidation. The aim of this work was to test the effect of an appropriate Ti metal surface treatment connected with hydride layer formation on the surface contact resistance and performance of the PEM water electrolyser.

\section{Experimental \\ $2.1 \quad$ Chemicals and materials}

Freshly prepared deionised water (conductivity $<1 \mu \mathrm{S}$ ) produced by DIWA deionisation system (WATEK, Czech Republic) was used in all experiments. The following chemicals and materials were used in the experiments: 35\% HCl (Lachner, Czech Republic), propan-2-ol (99.9\%, Penta, Czech Republic), acetone (99.9\%, Penta, Czech Republic), titanium felt (ST/TI/20/1050/77, Bekaert), $5 \%$ Nafion $^{\circledR}$ solution in propan-2-ol (D521, Ion Power), Nafion ${ }^{\circledR} 117$ membrane (Ion Power), 40\% Pt on carbon (HiSPEC4000, Johnson-Matthey), $\mathrm{IrO}_{2}$ (Premion ${ }^{\circledast}$, Alfa Aesar) and carbon felt GDL with microporous layer (SGL 38BC, Sigracet).

\subsection{Ti treatment, testing and analysis}


First, the Ti felt used in the experiments was degreased by washing with acetone and propan-2-ol. Afterwards, it was immersed in deionised water and ultrasonicated for 10 minutes in order to remove any mechanical impurities and fully flood its porous structure. After that it was placed into $35 \% \mathrm{HCl}$ solution (preheated under reflux to $54^{\circ} \mathrm{C}$ ) for a period of 5 minutes. The maximum applicable temperature was limited by the boiling point of $35 \% \mathrm{HCl}$ solution which is $55^{\circ} \mathrm{C}$. In order to be able to record open circuit potential of the felt during etching, the felt was contacted by Pt wire (not in contact with the solution) which is relatively resistant against $\mathrm{HCl}$ vapours. The etched felt was thoroughly rinsed with deionised water in order to remove reaction products and unreacted $\mathrm{HCl}$. The rinsed Ti felt was left to dry and then used for further experiments.

For electrochemical experiments a HEKA PG310 potentiostat was used. A two-electrode arrangement (with working and reference electrodes) was used to measure the open circuit potential of the Ti metal. An aqueous silver chloride reference electrode saturated with $\mathrm{KCl}$ was used in all the experiments and all the potential values in this work refer to its potential ( $+0.197 \mathrm{~V}$ vs. standard hydrogen electrode). The reference electrode was placed in a capillary filled with saturated $\mathrm{KCl}$ solution and separated from the solution studied by a ceramic porous frit.

The morphology of the Ti felt was studied using scanning electron microscopy (SEM, Hitachi S4700, Japan). Samples were fixed to the $\mathrm{Al}$ holder using conducting double sided carbon tape. The phase composition of the felts was determined from X-ray diffraction (XRD) spectra measured by a PANalytical X'Pert PRO X-ray diffractometer (PANanalytical, Netherlands) using a nickel beta-filter with $\mathrm{Cu} K \alpha$ radiation operated at $40 \mathrm{kV}$ and $30 \mathrm{~mA}$. The corresponding average wavelength was $1.5425 \AA$. XRD spectra were measured for angles between $5^{\circ}[2 \Theta]$ and $90^{\circ}[2 \Theta]$ with a step of $0.0394^{\circ}$ and scan rate of $3.2^{\circ}[2 \Theta] \mathrm{min}^{-1}$. An Axios sequential Xray fluorescence (XRF) spectrometer (PANanalysical, Holland) was used for qualitative and quantitative element analysis. It was equipped with a Rh anode end-window X-ray tube type 4GN fitted with a $75 \mu \mathrm{m} \mathrm{Be}$ window. The measurement time was about 20 minutes. X-ray photoelectron spectra (XPS) were measured using an ESCAProbeP (Omicron Nanotechnology Ltd, UK) electron spectrometer with a monochromatic $\mathrm{Al} \mathrm{K \alpha}$ source $(5.5 \mathrm{~mA}, 15 \mathrm{kV})$. The probed spot diameter was $0.8 \mathrm{~mm}$. High-resolution spectra (step size of $0.05 \mathrm{eV}$ ) were collected using pass energy of $30 \mathrm{eV}$. The spectra were corrected for the surface charging using the line of adventitious carbon at $284.8 \mathrm{eV}$. For the deconvolution of the spectra a commercial KolXPD software (version 1.8.0) was used [40]. A Shirley background was used during the spectra deconvolution. The ratio of Ti $2 \mathrm{p}_{3 / 2}$ and $2 \mathrm{p}_{1 / 2}$ line intensities was set 2:1. The peak of $\mathrm{Ti}^{0 / I I}$ (with metallic character) was fitted using an (asymmetric) Doniach Sunjic function convoluted with a Gaussian, all other peaks were fitted using the Voigt function. The peak-orbit splitting values of $6.0 \mathrm{eV}$ and $5.70 \mathrm{eV}$ were determined for $2 \mathrm{p}$ lines of $\mathrm{Ti}^{0 / \mathrm{II}}$ and $\left(\mathrm{Ti}^{\mathrm{III}} / \mathrm{Ti}^{\mathrm{IV}}\right)$, respectively, during deconvolution. These values correspond very well to those reported in the literature [41, 42].

\subsection{PEM water electrolysis}

The membrane electrode assembly was tested in a laboratory-scale single-cell PEM WE set-up. Titanium endplates were gold plated and possessed parallel flow channels defining an active area of $4 \mathrm{~cm}^{2}$. Catalyst coated membranes (CCM) were prepared on using a CNC airbrush by first spraying an anode catalyst ink on one side and subsequently a cathode catalyst ink on the other side of a Nafion ${ }^{\circledR} 117$ membrane. During the spraying, the membrane was placed on a bench heated to $130{ }^{\circ} \mathrm{C}$. The anode ink was composed of $\mathrm{IrO}_{2}, \mathrm{Nafion}^{\circledR}$ solution, deionised water and propan-2-ol mixed in the ratio: $1.00 \mathrm{~g}: 4.23 \mathrm{~cm}^{3}: 19.2 \mathrm{~cm}^{3}: 19.2 \mathrm{~cm}^{3}$. The cathode ink was prepared by mixing Pt/C catalyst, Nafion ${ }^{\circledR}$ solution and deionised water in the ratio: $1.00 \mathrm{~g}: 6.00 \mathrm{~cm}^{3}: 30 \mathrm{~cm}^{3}$. The anode catalyst layer contained $85 \mathrm{wt} . \%$ of $\mathrm{IrO}_{2}$ and $15 \mathrm{wt} . \%$ of Nafion ${ }^{\circledR}$. The total $\operatorname{Ir}\left(\mathrm{IrO}_{2}\right)$ loading was $0.75(0.875) \mathrm{mg} \mathrm{cm}^{-2}$. The cathode catalyst layer contained $77 \%$ of Pt/C catalyst and $23 \%$ of Nafion ${ }^{\circledR}$. The total Pt loading was $1 \mathrm{mg} \mathrm{cm}^{-2}$. Titanium felt and carbon felt with microporous layer were used as the anode and cathode gas diffusion layers, respectively. After the assembly the cell was constricted by a momentum of $8 \mathrm{Nm}$. A long-term electrolysis at a temperature of $60{ }^{\circ} \mathrm{C}$ was performed using a Statron 3251.0 stabilised power source (Statron, Germany). The testing procedure cycle consisted of 1 hour of operation at $1.8 \mathrm{~V}$, after which a load curve was measured from $1.8 \mathrm{~V}$ down to $1.3 \mathrm{~V}$ and back to $1.8 \mathrm{~V}$ in $0.05 \mathrm{~V}$ steps (the voltage in the range of $1.8 \mathrm{~V}$ to $1.5 \mathrm{~V}$ and $1.5 \mathrm{~V}$ to $1.3 \mathrm{~V}$ was stepped in 5-minute and 30-second intervals, respectively). For the 
measurement of the electrochemical impedance spectra the cell was disconnected from the power source and connected to a Solartron SI 1260 frequency response analyser in combination with a Solartron SI 1287 electrochemical interface (Solartron Analytical, United Kingdom). The impedance spectra were recorded (after a 5-minute stabilisation of the performance at the given voltage) in $0.1 \mathrm{~V}$ increments, starting from a cell voltage of $1.4 \mathrm{~V}$ in the frequency range of $65 \mathrm{kHz}$ to $0.1 \mathrm{~Hz}$ (voltage amplitude of $0.020 \mathrm{~V}$ ).

\section{Results and discussion}

\subsection{Ti felt modification and analysis}

A record of open circuit potential during etching of Ti felt in $35 \% \mathrm{HCl}$ at $54{ }^{\circ} \mathrm{C}$ is shown in Figure 1 . The passive layer breakdown is visible as a sudden drop in electrode potential from around $+0.1 \mathrm{~V}$ to $-0.62 \mathrm{~V}$ (vs. $\mathrm{Ag} / \mathrm{AgCl}$ ) after approximately $80 \mathrm{~s}$ of etching. This indicates relatively weak stability/low thickness of the passivation layer of the felt. The breakdown was accompanied by the commencement of active metal dissolution (forming $\mathrm{Ti}^{3+}$ species, as documented by the purple/blue colour of the etching solution) and intensive $\mathrm{H}_{2}$ gas evolution. $\mathrm{Ti}^{3+}$ species were later (upon standing) oxidised by $\mathrm{O}_{2}[26,43]$ (solution colour turned green). As is shown in the SEM pictures presented in Figure 2, the morphology of the Ti surface changed dramatically after only 5 minutes of etching. While the surface of the pristine felt wires (Figure 2A) was smooth, the surface of the etched sample (Figure 2B) was grater-like (documenting the formation of pits). The average wire diameter in the pristine felt was about $20 \mu \mathrm{m}$. The etching duration of 5 minutes was chosen using a simple optimisation procedure (results are not shown here). The main objectives during the optimisation were to achieve a visible (by SEM) change in the surface morphology and not to reduce the diameter of the wires substantially. Using the series of the felts etched for varying periods of time, the approximate rate of the diameter decrease was estimated to be about $0.55 \mu \mathrm{m} \mathrm{min}^{-1}$. At the same time, numerous wires were seriously damaged after only 20 minutes of etching due to which the felt started to lose its integrity.

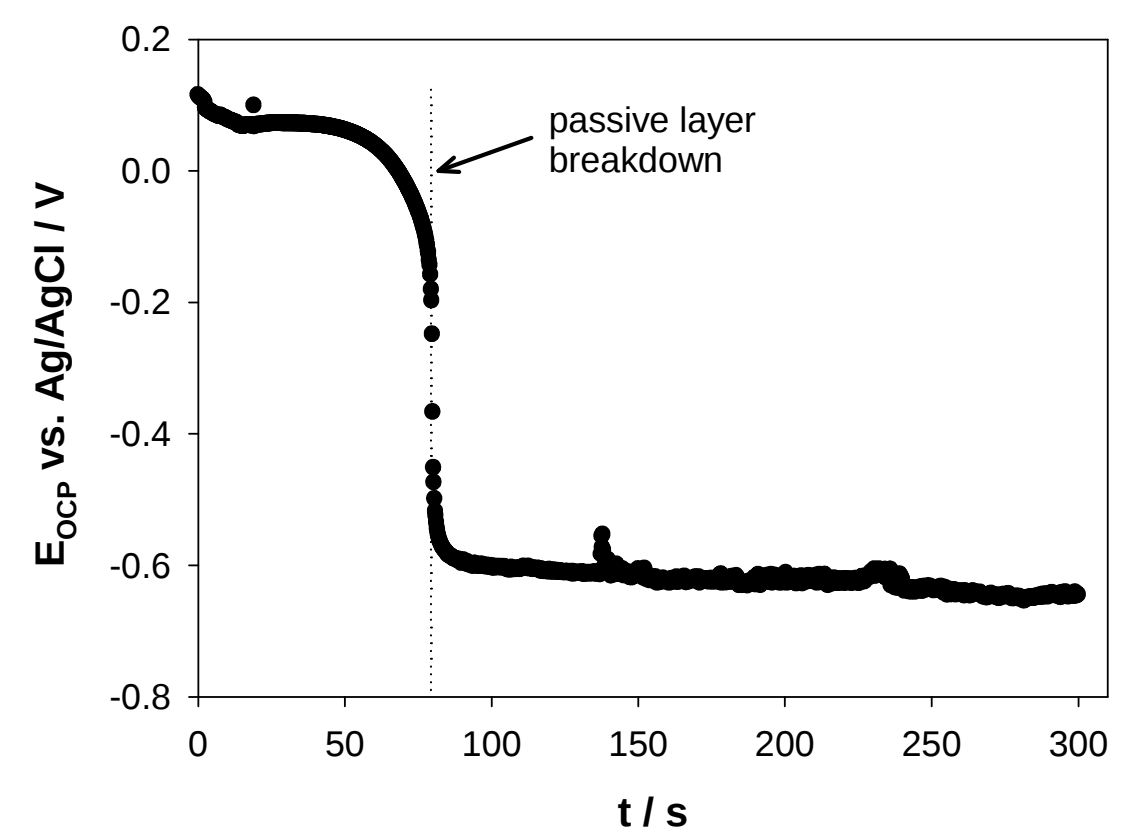

Figure 1: Development of the open circuit potential (E $\mathrm{ECP}_{\text {) }}$ during immersion of Ti felt in $35 \% \mathrm{HCl}$ at $54{ }^{\circ} \mathrm{C}$

Table 1: Composition of the Ti felt before and after 5 minutes of etching in $35 \% \mathrm{HCl}$ at $54{ }^{\circ} \mathrm{C}$ as determined from XRF measurements using $\mathrm{K} \alpha$ and $\mathrm{L} \alpha$ radiation. Values are given in wt. \%. Only elements with content $\geq$ $0.015 \%$ are shown. 


\begin{tabular}{|c|c|c|c|c|c|c|}
\hline $\begin{array}{c}\text { Pristin } \\
\mathbf{e}\end{array}$ & $\mathbf{T i}$ & $\mathbf{Y}$ & $\mathbf{F e}$ & $\mathbf{C a}$ & $\mathbf{S i}$ & $\mathbf{C l}$ \\
\hline $\mathrm{L} \alpha$ & 99.183 & 0.675 & 0.059 & 0.023 & 0.016 & 0.01 \\
\hline $\mathrm{K} \alpha$ & 99.781 & 0.075 & 0.061 & 0.023 & 0.016 & 0.009 \\
\hline Etched & & & & & & \\
\hline $\mathrm{L} \alpha$ & 99.913 & 0.036 & -- & -- & 0.016 & 0.015 \\
\hline $\mathrm{K} \alpha$ & 99.942 & 0.007 & -- & -- & 0.0016 & 0.015 \\
\hline
\end{tabular}

Further characterisation of the felt prior to and after etching was performed by XRF analysis. The results, from which several important conclusions can be drawn, are summarised in Table 1. Firstly, the pristine felt contains a certain amount of $Y(>0.65 \%)$ which is located near the surface of the individual wires. This can be concluded by comparing information obtained from the $L \alpha$ and $K \alpha$ lines. As the energy of the $L \alpha$ line is lower (than that of the $\mathrm{K} \alpha$ line), the $\mathrm{L} \alpha$ radiation detected originates at a lower depth and the corresponding information is, therefore, more surface-sensitive. The content of other impurities is quite negligible. Secondly, most of the $\mathrm{Y}$ is removed during etching. This again confirms the accumulation of $Y$ near the surface of the wires. The surface $Y$ impurities most likely originate from the Ti felt production process. It is important to bear in mind that, due to the origin of the fluorescence radiation, it practically does not allow the detection of elements lighter than boron. Also oxygen and nitrogen are detected with difficulties. Additional information about the sample microstructure and composition was obtained by $\mathrm{X}$-ray diffraction. The pristine sample diffraction spectrum contains peaks of Ti and $\mathrm{Y}_{2} \mathrm{O}_{3}$ whose content was semi-quantitatively estimated to be $<1 \%$. After the etching, the $\mathrm{Y}_{2} \mathrm{O}_{3}$ phase diffraction peaks disappeared. Instead, the patterns of various Ti hydrides are present in the diffractogram. The total Ti hydride content was about $5 \%$. The composition of the hydride phases in this particular case corresponded to $\mathrm{TiH}_{1.23}$ and $\mathrm{TiH}$. However, phases such as $\mathrm{TiH}_{0.85}$ or $\mathrm{TiH}_{1.5}$ were also detected during other experiments. The fact that the composition of Ti hydrides cannot be precisely controlled is in agreement with complicated nature of hydride formation [32]. In any case, these results confirm the effective removal of the passivation layer and formation of a reasonable amount of hydride phase at the (sub)surface of the individual Ti felt wires. The potential effect of the presence of $\mathrm{Y}_{2} \mathrm{O}_{3}$ on hydride phase formation was not, at this stage, investigated.

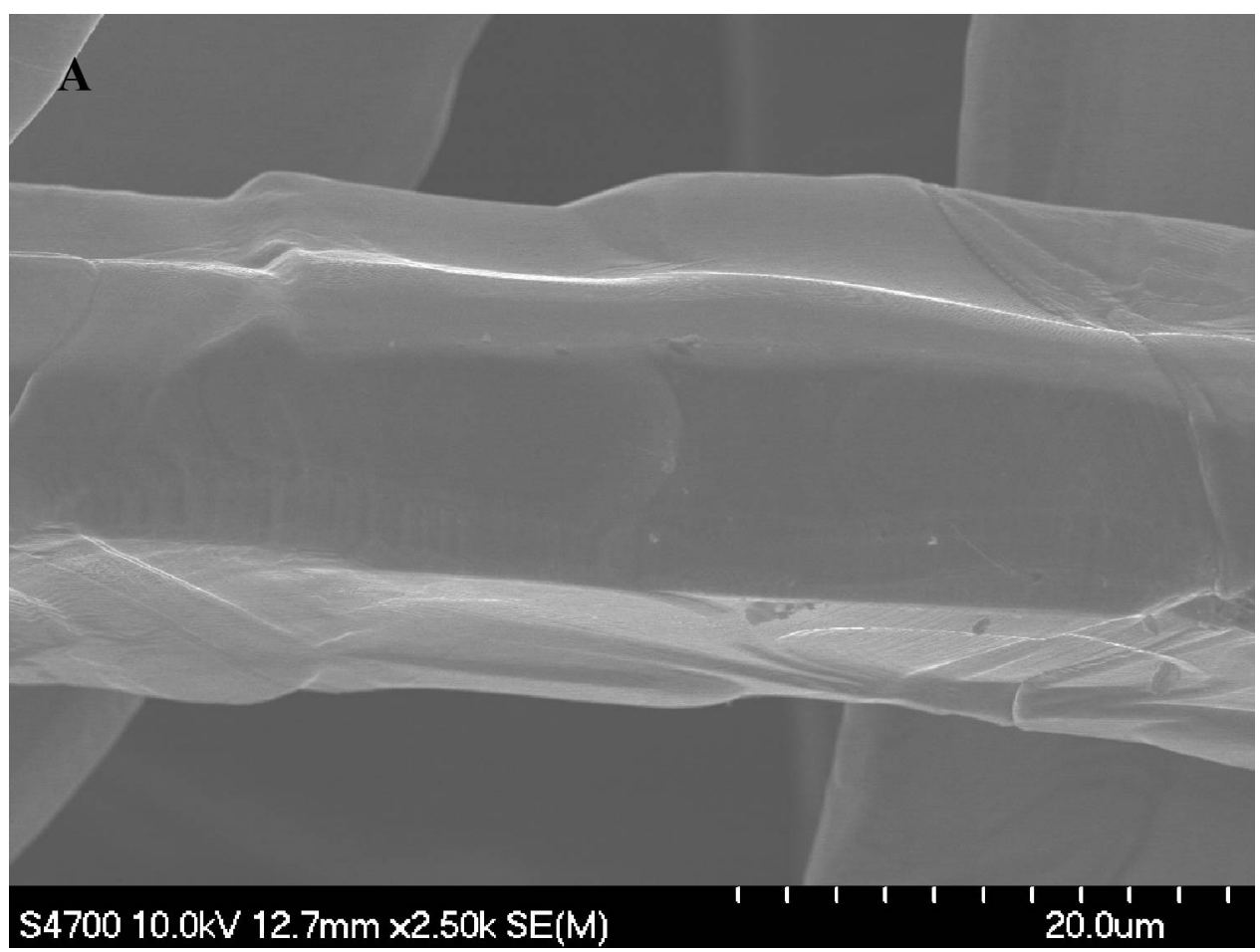




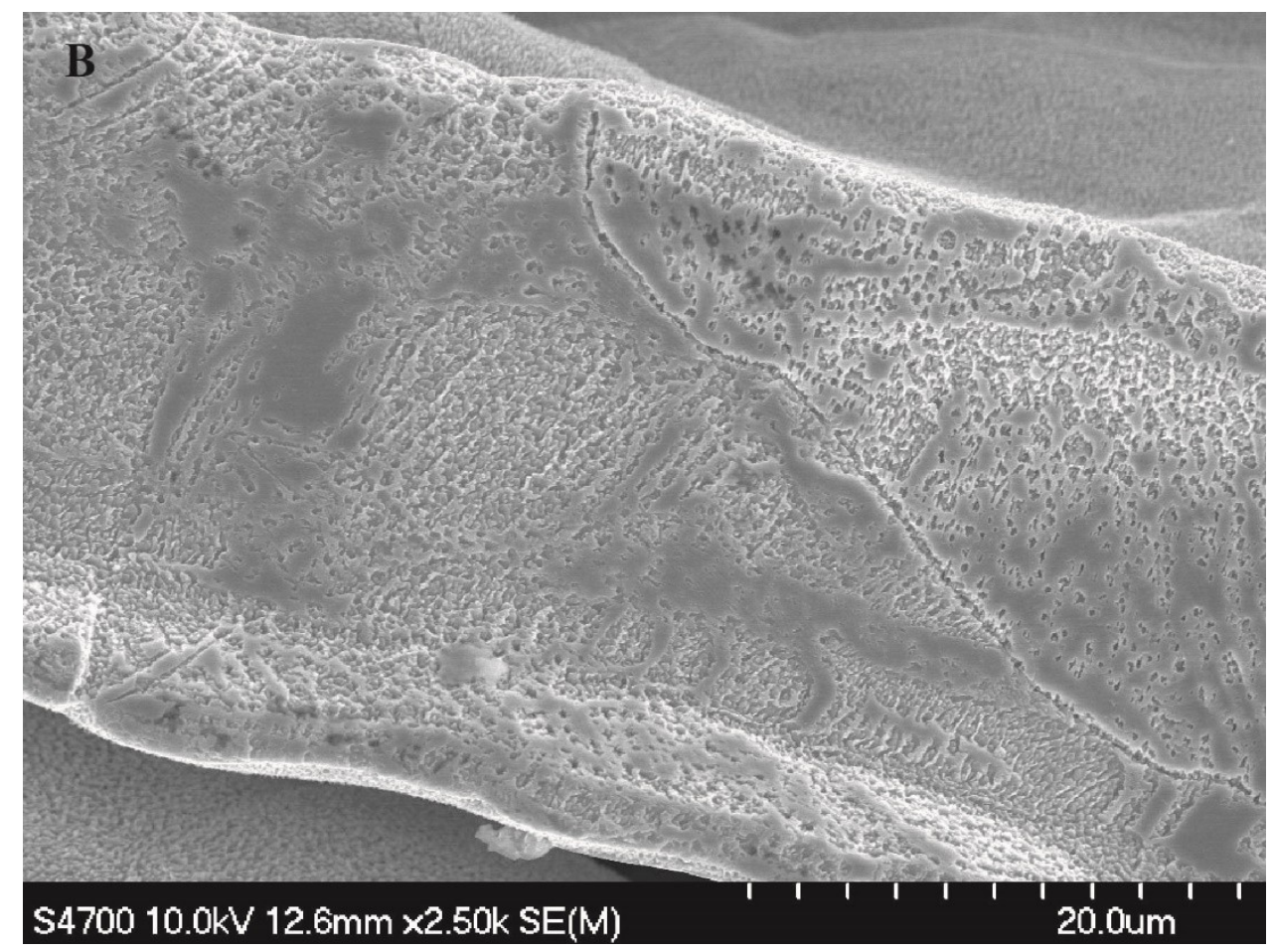

Figure 2: SEM picture of the Ti felt before (A) and after etching (B) in $35 \% \mathrm{HCl}$ at $54{ }^{\circ} \mathrm{C}$ for $300 \mathrm{~s}$

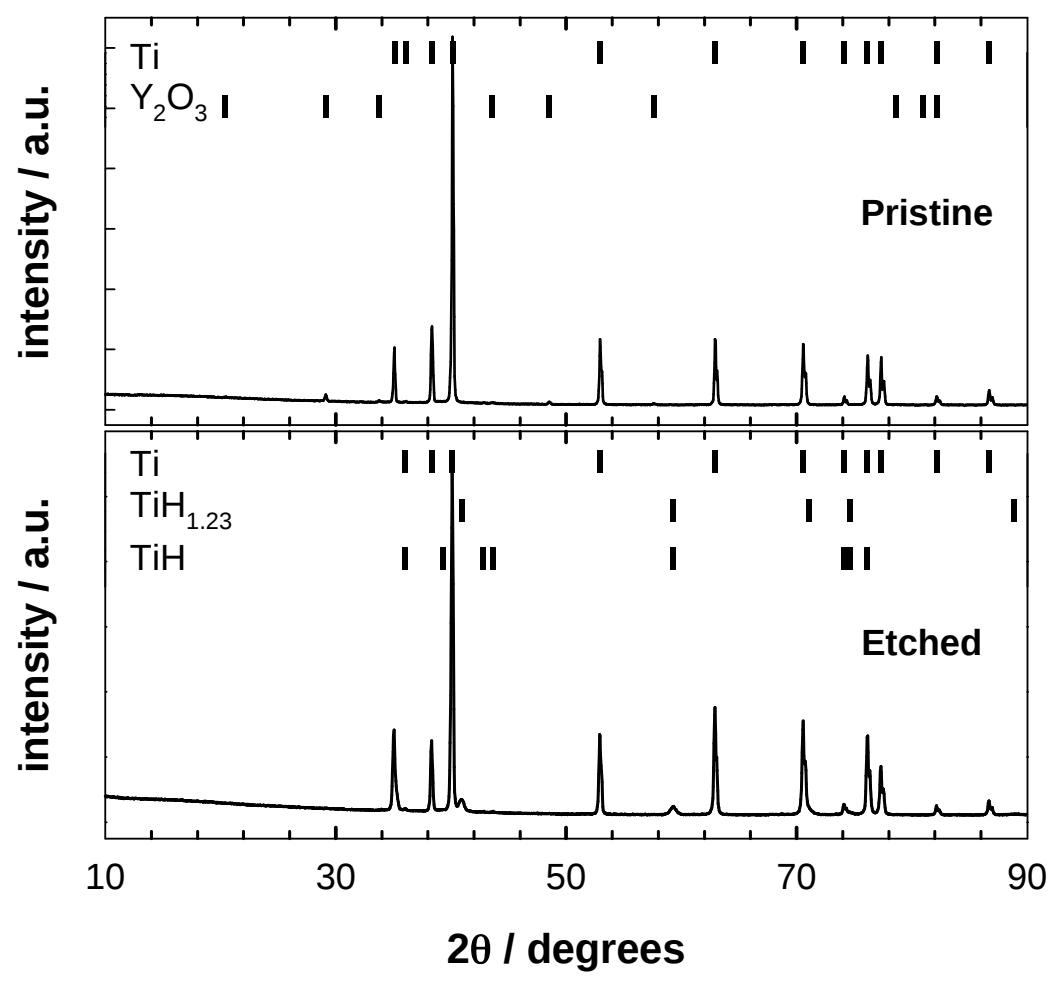

Figure 3: XRD spectra of the Ti felt before (pristine) and after etching (etched) in $35 \% \mathrm{HCl}$ at $54{ }^{\circ} \mathrm{C}$ for $300 \mathrm{~s}$. The diffraction peak positions of individual phases are shown in the upper part of the plots

Further interesting information about the state of the Ti felt surface was obtained by XPS. Ti 2p XPS spectra (and their deconvolution) are presented in Figure 4. In order to simplify the discussion of the Ti 2p spectra 
shown in Figure 4, only $2 \mathrm{p}_{3 / 2}$ lines are discussed here. The positions of the $2 \mathrm{p}_{1 / 2}$ lines can easily be calculated from the spin-orbit splitting values given in the experimental section. The Ti $2 \mathrm{p}$ spectrum of pristine Ti felt shown in Figure $4 \mathrm{~A}$ is dominated by the $2 \mathrm{p}_{3 / 2}$ line of $\mathrm{Ti}^{\mathrm{IV}}$ (at $458.6 \mathrm{eV}$ ). The lines attributable to the Ti species in the lower oxidation states are barely visible, which corresponds to the predominance of $\mathrm{Ti}^{\mathrm{IV}}$ in the spectrum of $\mathrm{TiO}_{2}$ in the passive layer [42]. Etching the felt changes its surface composition dramatically. This is documented by the spectrum shown in Figure 4B, where spectral lines of $\mathrm{Ti}^{0 / \mathrm{III}}$ and $\mathrm{Ti}^{\mathrm{III}}$ species (at $454.3 \mathrm{eV}$ and $456.2 \mathrm{eV}$ ) become significant. Lamartine et al. reported that the energy of the Ti $2 \mathrm{p}_{3 / 2}$ line of Ti hydride increases linearly (compared to the Ti metal line at $454.2 \mathrm{eV}$ ) with a rising amount of hydrogen (slope of about $+0.3 \mathrm{eV}$ per unit of $\mathrm{H} / \mathrm{Ti}$ atomic ratio) [44]. Therefore, taking into account some degree of uncertainty in the metallic Ti peak position, it is difficult to distinguish between the metal Ti and low-hydrogen content Ti hydride species. In order to account for this uncertainty, we assign these species to $\mathrm{Ti}^{0 / \mathrm{II}}$, which relates to the potential span of the oxidation states in the range of 0 to $+\mathrm{II}$. At the same time, the intensity of the spectral line due to $\mathrm{Ti}^{\mathrm{IV}}$ is rather low. In order to estimate the stability of the Ti hydride layer under ambient conditions, an additional spectrum of the etched Ti felt sample aged for 7 months (air, atmospheric pressure, room temperature) was measured. This is shown in Figure 4C. It is apparent from the intensity of individual lines that the aged surface is somewhat more oxidised compared to the freshly etched sample, but its surface is still oxidised to a lesser extent than that of the pristine felt.

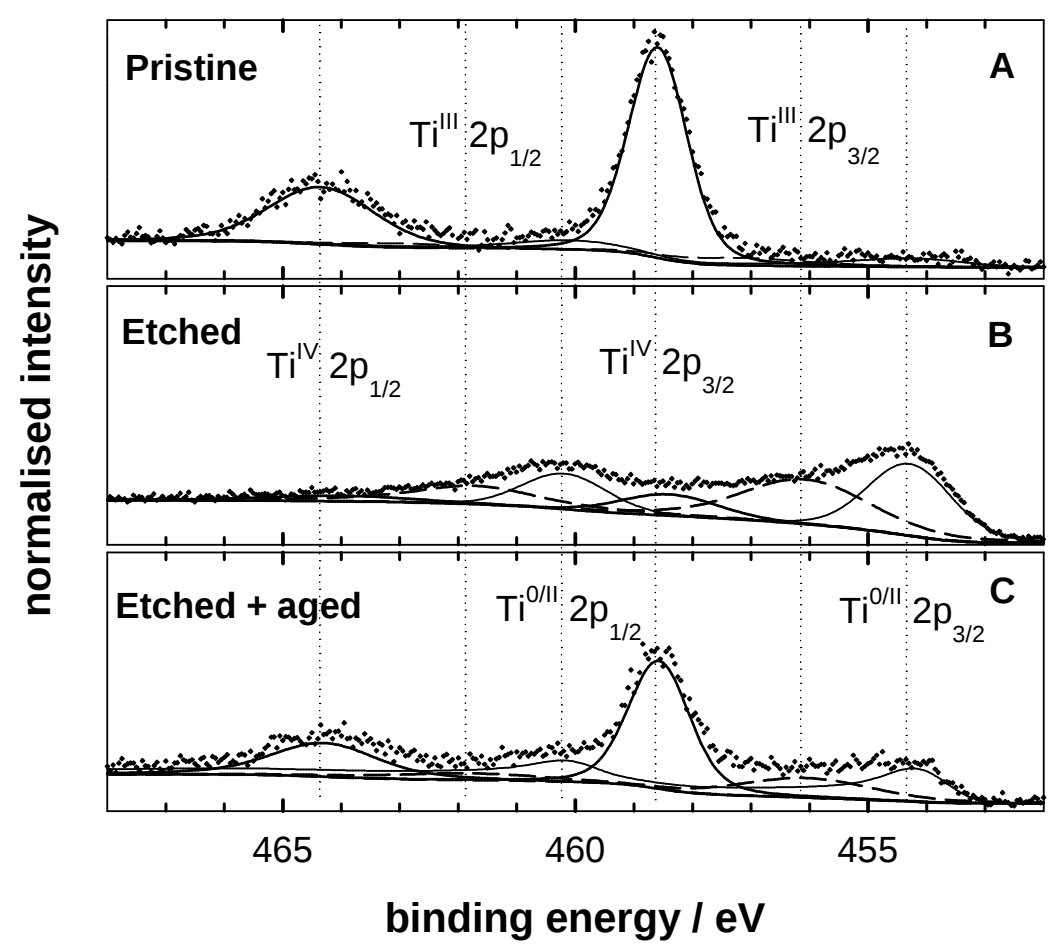

Figure 4: Ti 2p XPS spectra of the pristine, etched and etched Ti felt aged for 7 months in air at room temperature. Spectra were normalised to the integral area of unity. Positions of the individual Ti $2 \mathrm{p}$ lines are indicated by vertical dotted lines and assigned in the figure

The compositions of the Ti surfaces (with regard to Ti species) are summarised in the bar plot in Figure 5. It was obtained by comparing the integral areas of the individual considered Ti species observed and determined by deconvolution of the Ti 2p spectral lines, as discussed previously in the context of Figure 4. Before etching, 84 $\%$ of the Ti species in the surface layer is present in the highest oxidation state, i.e. IV. Only 7 and $9 \%$ of the Ti 
exists in oxidation states 0/II and III, respectively. Contrary to this, the etched surface contains only $15 \%$ of $\mathrm{Ti}^{\mathrm{IV}}$, while the concentration of $\mathrm{Ti}^{0 / \mathrm{III}}(41 \%)$ and $\mathrm{Ti}^{\mathrm{III}}(44 \%)$ is quite high. The composition after aging $\left(20 \% \mathrm{Ti}^{0 / I I}\right.$, $21 \% \mathrm{Ti}^{\mathrm{III}}$ and $59 \%$ of $\mathrm{Ti}^{\mathrm{IV}}$ ) lies somewhere between the two extreme cases. It is interesting to note that the atomic ratio of $\mathrm{Ti}^{0 / I I}$ and $\mathrm{Ti}^{\mathrm{III}}$ is very close to unity in all cases.

Oxygen (O 1s) XPS spectra are presented in Figure 6. The spectra of the pristine and aged samples are very similar and are dominated by the line at $530.1 \mathrm{eV}$ documenting the presence of $\mathrm{O}$ in the lattice of $\mathrm{TiO}_{2}$ on the very surface. Less intensive lines at higher binding energy are related to more weakly bound oxygen species, such as adsorbed $\mathrm{OH}(531.7 \mathrm{eV})$ and adsorbed water $(533.5 \mathrm{eV})$ [45]. On the other hand, the highest photoelectron intensity, in the case of the etched sample, was observed for a binding energy of $530.9 \mathrm{eV}$. This can be partially explained by the lower oxidation state of the surface layer Ti species leading to a weaker bond between $\mathrm{O}$ and $\mathrm{Ti}$. What is not visible from the $\mathrm{O}$ 1s spectra normalised to unit area is the differences in the overall $\mathrm{O}$ content in the surface layer. This becomes apparent when $\mathrm{O} 1 \mathrm{~s}$ and Ti $2 \mathrm{p}$ integral signals are compared. Using the atomic sensitivity factors (1.798 for Ti $2 \mathrm{p}$ and 0.711 for $\mathrm{O} 1 \mathrm{~s}$ [46]) the atomic ratio of O/Ti can be estimated. The estimated values for the pristine, etched and (etched + ) aged sample are 3.3, 1.1 and 2.2, respectively. The value of 3.3 exceeds the expected stoichiometric coefficient $\mathrm{O}\left(\mathrm{in}_{\mathrm{TiO}}\right)$ of 2 . However, this is reasonable as part of the $\mathrm{O}$ is present in the form of adsorbed $\mathrm{OH}$ and $\mathrm{H}_{2} \mathrm{O}$, as discussed above. The low content of $O(1 / 3$ of the $O$ in the pristine sample) in the etched sample is in agreement with the removal of the existing passivation layer and the formation of a new thin layer on top of the Ti hydrides. Finally, ageing (for 7 months, air, room temperature) of the etched sample led to doubling of the $\mathrm{O}$ (in the form of $\mathrm{O}^{2-}$ ) content (corresponding to $2 / 3$ of the $\mathrm{O}$ amount in the pristine sample).

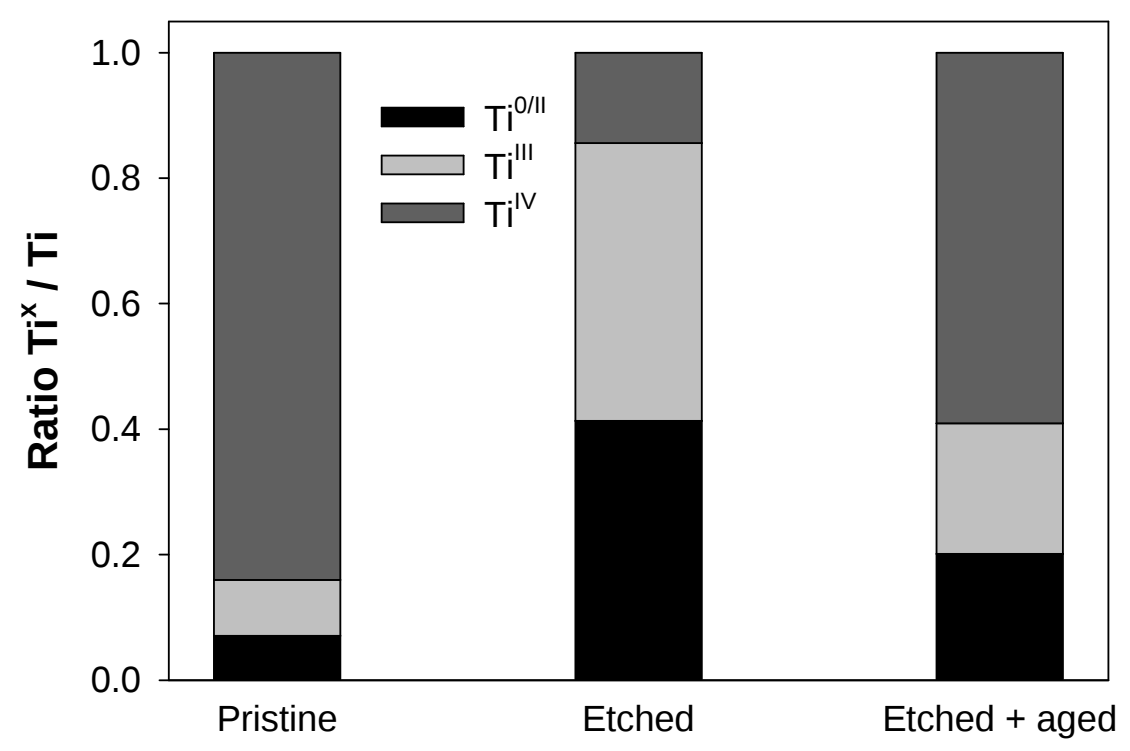

Figure 5: Distribution of oxidation states of Ti in the Ti felts after various treatments determined from the XPS spectra presented in Figure 4

When thinking about the change in the composition of the passivation layer in radial direction, it is first useful to define the thickness of the layer probed by XPS. The mean free path of Ti $2 \mathrm{p}$ (and similarly O 1s) photoelectrons in $\mathrm{Ti}$ and $\mathrm{TiO}_{2}$ lies within the range of 1.6-2.0 nm, therefore most of the information comes from the upper 5-6 $\mathrm{nm}$ [47]. Secondly, it is reasonable to assume that the majority of the $\mathrm{Ti}^{\mathrm{IV}}$ is located on the very surface of the material and its content decreases when entering the material bulk. Deeper in the material, the passive layer contains more $\mathrm{Ti}^{\mathrm{III}}$ and $\mathrm{Ti}^{\mathrm{II}}$. Even deeper, a Ti hydride subsurface layer is present (between the thin passive oxide layer and the bulk of the Ti metal). It is likely that all the interfaces are fairly diffuse. This overall image is also in agreement with previous conclusions of Lu et al. [12]. They performed angle resolved XPS 
measurements of the Ti passivation layer and found out that (besides $\mathrm{Ti}^{\mathrm{IV}}$ ) $\mathrm{Ti}^{\mathrm{III}}$ ions are present in the passivation layer towards the side in contact with the surrounding environment, while $\mathrm{Ti}^{\mathrm{II}}$ ions are located at the interface of the passivation layer and the metallic phase. In general, the concentration and distribution of the individual Ti ion types in the layer is important since it greatly influences the resistance of the layer, which has great practical implications for the surface contact resistance value.

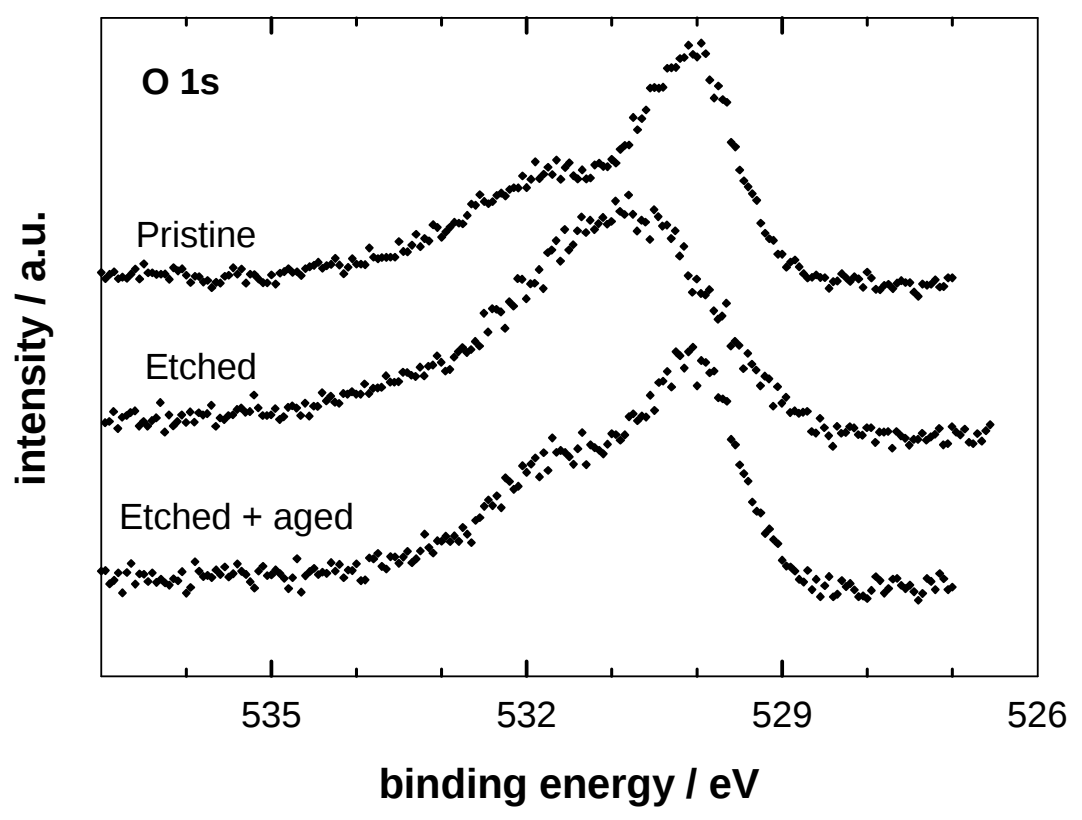

Figure 6: O 1s XPS spectra of the pristine, etched and etched Ti felt aged for 7 months in air at room temperature. Spectra were normalised to the integral area of unity

\subsection{PEM water electrolysis tests}

The performance of the etched Ti felt was tested in a PEM water electrolyser. The results are summarised in Figure 7. The load curves recorded at various times during PEM WE operation presented in Figure 7A document an important differences between the performance of the etched and the pristine (not etched) Ti felt. From the very beginning of the electrolysis, the current densities obtained using the electrolyser with etched Ti felt were almost two times higher in the whole range of cell voltages applied. Moreover, the difference in performance increased with time. The performance of the cell with the etched felt did not change throughout the 108 hour-long operation. Actually, the performance even slightly improved, but the improvement is most likely related to some phenomena unrelated to passivation, such as catalyst activation. On the other hand, the current densities substantially dropped in the cell containing unmodified felt. Such behaviour can be explained by taking the ohmic resistance of the system into account. In order to get more information about the system behaviour, the electrochemical impedance spectra of the PEM water electrolyser cell were measured in the range from $1.4 \mathrm{~V}$ to $1.6-1.8 \mathrm{~V}$ in $0.1 \mathrm{~V}$ increments. The upper voltage range was given by the maximum current range (2 A) allowed by the used apparatus. Examples of the electrochemical impedance spectra obtained in the case of PEM water electrolyser with the pristine and the etched Ti felts at cell voltage of $1.6 \mathrm{~V}$ are shown in Figure 7B. Firstly, in a high frequency region, there is clear dominating effect of inductance which is present due to induction in the massive electrolyser body (this feature is present also if the cell is assembled without Nafion membrane and catalytic layers on the gas diffusion layers). Secondly, there is large difference in the ohmic resistance between the pristine and the etched Ti felt. A lower ohmic resistance in the case of the etched Ti felt leads to lower ohmic losses in the system and consequently a lower potential on the cathode and, what is most important, a higher anode potential. This results in the increased rate of electrode reactions, which is in accordance with a lower activation resistance (documented by smaller "diameter" of the semicircle in the 
Nyquist diagram) of the etched felt. The development of ohmic resistance values determined by electrochemical impedance spectroscopy are shown in Figure 7C. A slightly apparent scattering of the values is given by the fact that the impedance spectra were each time measured at several cell voltages and the ohmic resistance slightly increased with cell voltage. The ohmic resistance of the cell with etched felt was fairly low and remained practically constant (changes from $0.23 \Omega \mathrm{cm}^{2}$ at the time of $0.5 \mathrm{~h}$ to $0.24 \Omega \mathrm{cm}^{2}$ at the time of $103 \mathrm{~h}$ ). This corresponds to the "degradation rate" of $1 \cdot 10^{-4} \Omega \mathrm{cm}^{2} \mathrm{~h}^{-1}$. At the beginning of electrolysis (time of $6 \mathrm{~h}$ ), the ohmic resistance of the cell with pristine Ti felt already reached a value of $0.46 \Omega \mathrm{cm}^{2}$ and then dramatically increased (to about $0.64 \Omega \mathrm{cm}^{2}$ after only 30 hours of electrolysis). Using the whole duration of the experiment of about $80 \mathrm{~h}$ for the degradation rate calculation, the degradation rate can be estimated to be at least $23 \cdot 10^{-4} \Omega \mathrm{cm}^{2} \mathrm{~h}^{-1}$. When comparing these values, the difference of about $0.2 \Omega \mathrm{cm}^{2}$ at the beginning of the electrolysis can be assigned to the effect of additional surface contact resistance of the original passivation layer. An additional $0.18 \Omega \mathrm{cm}^{2}$ increase can be attributed to a further consolidation of the passivation layer of the pristine felt during approximately 80 hours of operation.

After the electrolysis, the cell was disassembled and the etched Ti felt was analysed by XRD and XPS. The XDR spectrum shown in Figure 8A reveals the presence of Ti hydrides (mainly $\mathrm{TiH}_{1.5}$ and $\mathrm{TiH}$ ) in the felt even after more than 100 hours of PEM water electrolyser operation (cell voltage of up to $1.8 \mathrm{~V}, 60^{\circ} \mathrm{C}$ ). This shows reasonable stability of the Ti hydrides under the conditions of PEM WE and explains the stable performance of the electrolyser containing the etched Ti felt. A different sample of etched felt, whose spectra is not presented in Figure 3B, was used in electrolysis cell, therefore, the hydride phase composition differs slightly $\left(\mathrm{TiH}_{1.5}\right.$ phase is present instead of $\mathrm{TiH}_{1.23}$ ). The deconvoluted XPS spectrum of the felt after electrolysis (Figure 8B) documents the fact that the probed 5-6 nm surface layer is largely oxidised $\left(6 \% \mathrm{Ti}^{0 / I I}, 5 \% \mathrm{Ti}^{\mathrm{III}}\right.$ and $89 \%$ of $\left.\mathrm{Ti}^{\mathrm{IV}}\right)$. Thus, the hydrides detected by the XRD must be present deeper under the surface of the Ti felt wires. Admittedly, in this case, the precision of the deconvolution was impaired by the low intensity of the signal which was most likely caused by contamination of the surface with traces of Nafion ${ }^{\circledR}$ and $\mathrm{IrO}_{2}$ from the anode side of the CCM. The fact that the surface contact resistance was still much smaller than in the case of the pristine felt (before and after electrolysis) suggests either the presence of a thicker/compact passive layer in the latter case or a difference in the microstructure or composition of the passive layer. We are currently performing further tests in order to evaluate the stability of the etched Ti felt over a longer timescale. 

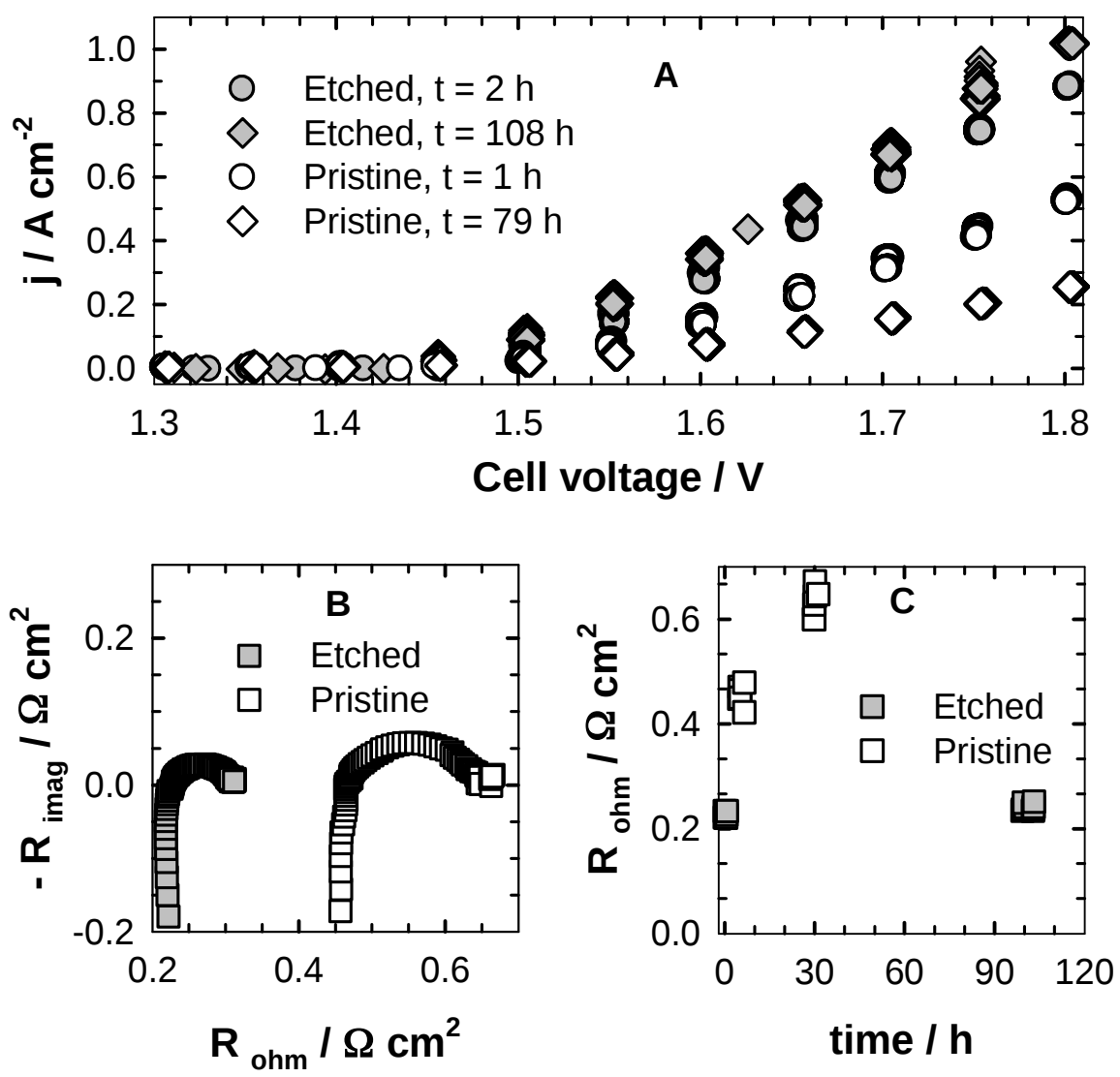

Figure 7: (A) Load curves of PEM WE cell operated at $60{ }^{\circ} \mathrm{C}$ (anode loading of $0.75 \mathrm{mg}_{\mathrm{Ir}} \mathrm{cm}^{-2}$, cathode loading of $1 \mathrm{mg}_{\mathrm{Pt}} \mathrm{cm}^{-2}$ ). Duration of the cell operation is given in the figure inset. Multiple points visible for the same voltage are result of development/stabilisation of the current density during constant voltage step. (B) Examples of the obtained electrochemical impedance spectra obtained in the case of PEM water electrolyser with the pristine and the etched Ti felts, spectra obtained at cell voltage of $1.6 \mathrm{~V}$ at the beginning of the PEM WE operation. (C) Overall ohmic resistance $\mathrm{R}_{\mathrm{ohm}}$ of the PEM water electrolysis cells (containing pristine and etched Ti felt) determined by electrochemical impedance spectroscopy. Multiple points visible for the same voltage are present since ohmic resistance values obtained at all measured cell voltages are presented in the figure. 

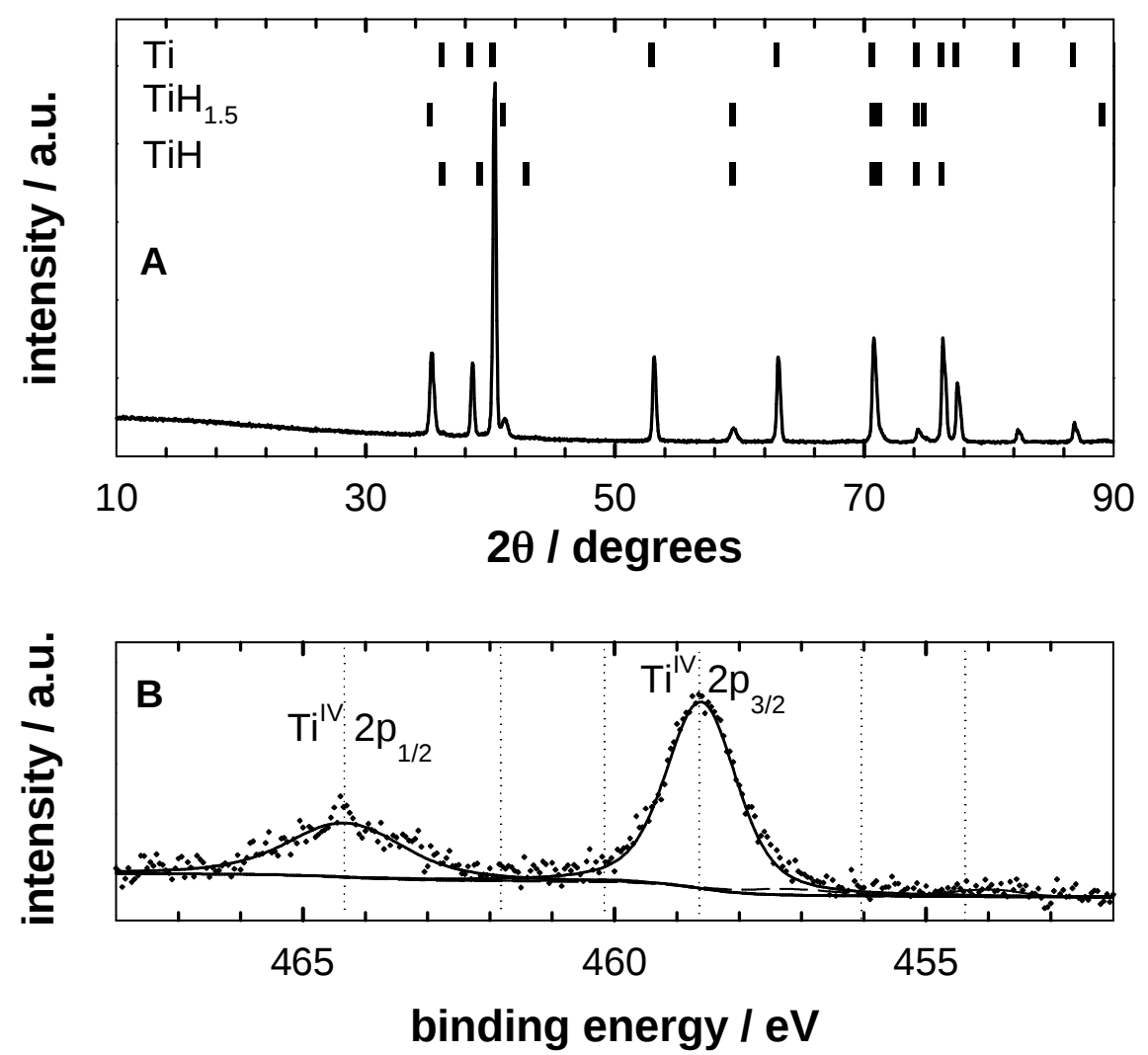

Figure 8: (A) XRD spectra of the etched Ti felt after 108 hours of PEM WE operation. The diffraction peak positions for individual phases are shown in the upper part of the plots. (B) Ti 2p XPS spectra of the etched Ti felt after 108 hours of PEM WE operation. The positions of the dominant Ti 2p lines are indicated by vertical dotted lines and are assigned in the figure

\section{Conclusions}

The results have shown that the above described surface modification of Ti by etching (in hydrochloric acid) represents a highly interesting procedure for increasing Ti resistance to excessive passivation which leads to a substantial increase in the surface contact resistance. The superior performance of the etched Ti gas diffusion layer in a PEM water electrolyser was confirmed during a (>100 hour) experiment using current densities of up to $1 \mathrm{~A} \mathrm{~cm}^{-2}$. The effect was ascribed to the protective function of a Ti hydride underlayer formed during etching in acid. It was found that, by using a treatment of this type, the surface contact resistance can not only be directly reduced, but its increase during PEM WE operation can be largely supressed. The potential of the described surface modification becomes even more apparent in view of the fact that currently the only alternative is coating the Ti surface with expensive precious metals such as Pt. It is obvious that the simple surface modification procedure described has huge energy savings potential for PEM WE operation. 


\section{Acknowledgement}

Financial support of this work by the Grant Agency of the Czech Republic within the framework of Project No. 15-02407J and by the Deutsche Forschungsgemeinschaft, Grant no. HA6841/2-1 and no. SU189/7-1, is gratefully acknowledged. Part of the material characterisation experiments was performed utilising instrumentation financed by the Operational Programme Prague - Competitiveness (CZ.2.16/3.1.00/24501) and the "National Program of Sustainability“ (NPU I LO1613) MSMT-43760/2015.

[1] M. Carmo, D.L. Fritz, J. Mergel, D. Stolten, A comprehensive review on PEM water electrolysis, Int. J. Hydrogen Energy, 38 (2013) 4901-4934.

[2] M. Paidar, V. Fateev, K. Bouzek, Membrane electrolysis-History, current status and perspective, Electrochim. Acta, 209 (2016) 737-756.

[3] L. Barreto, A. Makihira, K. Riahi, The hydrogen economy in the 21st century: a sustainable development scenario, Int. J. Hydrogen Energy, 28 (2002) 267-284.

[4] L. Bertuccioli, A. Chan, D. Hart, F. Lehner, B. Madden, E. Standen, Development of Water Electrolysis in the European Union, Fuel cells and hydrogen Joint undertaking, (2014).

[5] M.H. Miles, M.A. Thomason, Periodic Variations of Overvoltages for Water Electrolysis in Acid Solutions from Cyclic Voltammetric Studies, J. Electrochem. Soc., 123 (1976) 1459-1461.

[6] M. Pourbaix, Atlas of electrochemical equilibria in aqueous solutions, 2 nd ed., National Association of Corrosion Engineers, Houston, Texas, 1974.

[7] J.E. Draley, Corrosion of Valve Metals, Corrosion Chemistry, Am. Chem. Soc. 1979, pp. 185-234.

[8] C. Veiga, J. Davim, A. Loureiro, Properties and applications of titanium alloys: A brief review, 2012.

[9] X. Liu, P.K. Chu, C. Ding, Surface modification of titanium, titanium alloys, and related materials for biomedical applications, Materials Science and Engineering: R: Reports, 47 (2004) 49-121.

[10] N. Sato, An overview on the passivity of metals, Corros. Sci., 31 (1990) 1-19.

[11] R.G. Breckenridge, W.R. Hosler, Electrical Properties of Titanium Dioxide Semiconductors, Phys. Rev., 91 (1953) 793-802.

[12] G. Lu, S.L. Bernasek, J. Schwartz, Oxidation of a polycrystalline titanium surface by oxygen and water, Surf. Sci., 458 (2000) 80-90.

[13] B.-S. Lee, H.-Y. Park, I. Choi, M.K. Cho, H.-J. Kim, S.J. Yoo, D. Henkensmeier, J.Y. Kim, S.W. Nam, S. Park, K.-Y. Lee, J.H. Jang, Polarization characteristics of a low catalyst loading PEM water electrolyzer operating at elevated temperature, J. Power Sources, 309 (2016) 127-134.

[14] V. Fateev, P. Blach, S. Grigoriev, A. Kalinnikov, V. Porembskiy, High pressure PEM electrolyzers and their application for renewable energy systems, European Hydrogen Energy Conference 2014 Seville, Spain, 2014.

[15] M. Stern, H. Wissenberg, The Influence of Noble Metal Alloy Additions on the Electrochemical and Corrosion Behavior of Titanium, J.Electrochem. Soc., 106 (1959) 759-764.

[16] H.B. Beer, The Invention and Industrial Development of Metal Anodes, J. Electrochem. Soc., 127 (1980) 303C-307C.

[17] G.P. Vercesi, J. Rolewicz, C. Comninellis, J. Hinder, Characterization of dsatype oxygen evolving electrodes. Choice of base metal, Thermochim. Acta, 176 (1991) 31-47.

[18] N.T. Thomas, K. Nobe, Corrosion Behavior of Titanium in $\mathrm{HCl}$, Corros., 29 (1973) 188-191.

[19] J.M. Peters, J.R. Myers, Anodic Polarization Behavior of Titanium and Titanium Alloys in Sulfuric Acids, Corros., 23 (1967) 326-330. 
[20] M.M. Hefny, A.G. Gad Allah, S.A. Salih, M.S. El-Basiouny, Nature of the Corrosion Reaction at the Anodic Oxide Film on Titanium in $\mathrm{HCl}$ Solutions, Corros., 40 (1984) 245-249.

[21] A.A. Mazhar, F.E.-T. Heakal, A.G. Gad Allah, Anodic Behavior of Titanium in Aqueous Media, Corros., 44 (1988) 705-710.

[22] J. Liu, A. Alfantazi, E. Asselin, Influence of Cupric, Ferric, and Chloride on the Corrosion of Titanium in Sulfuric Acid Solutions Up to $85^{\circ} \mathrm{C}$, Corros., 70 (2014) 2937.

[23] J. Krýsa, R. Mráz, I. Roušar, Corrosion rate of titanium in H2SO4, Mater. Chem. Phys., 48 (1997) 64-67.

[24] D.-S. Kong, Y.-Y. Feng, Electrochemical Anodic Dissolution Kinetics of Titanium in Fluoride-Containing Perchloric Acid Solutions at Open-Circuit Potentials, J. Electrochem. Soc., 156 (2009) C283-C291.

[25] G.A. El-Mahdy, Formation and Dissolution Behavior of Anodic Oxide Films on Titanium in Oxalic Acid Solutions, Corros., 63 (2007) 299-306.

[26] M.E. Straumanis, P.C. Chen, The Corrosion of Titanium in Acids-The Rate of Dissolution in Sulfuric, Hydrochloric, Hydrobromic and Hydroiodic Acids, Corros., 7 (1951) 229-237.

[27] M.E. Straumanis, P.C. Chen, The Mechanism and Rate of Dissolution of Titanium in Hydrofluoric Acid, J. Electrochem. Soc., 98 (1951) 234-240.

[28] G.R. Caskey, Diffusion of tritium in rutile (TiO2), Mater. Sci. Eng., 14 (1974) 109-114.

[29] Y. Fukai, Phase Diagrams of Transition Metal-Hydrogen Systems, J. Japn. Inst. Met., 55 (1991) 17-21.

[30] L.C. Covington, The Influence of Surface Condition and Environment on the Hydriding of Titanium, Corros., 35 (1979) 378-382.

[31] V.L. Stout, M.D. Gibbons, Gettering of Gas by Titanium, J. Appl. Phys., 26 (1955) 1488-1492.

[32] G. W. Wille, J.W. Davis, Hydrogen in Titanium Alloys, DEPARMENT OF ENERGY, (1981).

[33] I.I. Phillips, P. Poole, L.L. Shreir, Hydride formation during cathodic polarization of $\mathrm{Ti}-$ II. Effect of temperature and $\mathrm{pH}$ of solution on hydride growth, Corros. Sci., 14 (1974) 533-542.

[34] D.J. Blackwood, L.M. Peter, H.E. Bishop, P.R. Chalker, D.E. Williams, A sims investigation of hydrogen penetration of titanium electrodes, Electrochim. Acta, 34 (1989) 1401-1403.

[35] T. Mizuno, T. Shindo, T. Morozumi, Growth Rate of Hydride Layer Produced on Titanium Surface by Cathodic Polarization, Corros. Eng., 26 (1977) 185-193.

[36] C.L. Briant, Z.F. Wang, N. Chollocoop, Hydrogen embrittlement of commercial purity titanium, Corros. Sci., 44 (2002) 1875-1888.

[37] S. Samal, S. Cho, D.W. Park, H. Kim, Thermal characterization of titanium hydride in thermal oxidation process, Thermochim. Acta, 542 (2012) 46-51.

[38] A.R. Gromov, N.N. Kouznetsova, S.L. Yudina, V.V. Lunin, The investigation of titanium hydride oxidation process, J. Alloys Compd., 261 (1997) 269-272.

[39] M. Ito, D. Setoyama, J. Matsunaga, H. Muta, K. Kurosaki, M. Uno, S. Yamanaka, Electrical and thermal properties of titanium hydrides, J. Alloys Compd., 420 (2006) 25-28.

[40] http://www.kolibrik.net/science/kolxpd/. Accessed 1.10.2017

[41] U. Diebold, T.E. Madey, TiO2 by XPS, Surf. Sci. Spectra, 4 (1996) 227-231.

[42] R.L. Kurtz, V.E. Henrich, Comparison of Ti $2 p$ Core-Level Peaks from TiO2, Ti2O3, and Ti Metal, by XPS, Surf. Sci. Spectra, 5 (1998) 179-181.

[43] F. Fasmin, B.V.S. Praveen, S. Ramanathan, A Kinetic Model for the Anodic Dissolution of $\mathrm{Ti}$ in HF in the Active and Passive Regions, J. Electrochem. Soc., 162 (2015) H604-H610. 
[44] B.C. Lamartine, T.W. Haas, J.S. Solomon, Characterization of TiHx and TiD0.9 surfaces: AES, ELS, SIMS and XPS studies, Appl. Surf. Sci., 4 (1980) 537-555.

[45] M.J. Jackman, A.G. Thomas, C. Muryn, Photoelectron Spectroscopy Study of Stoichiometric and Reduced Anatase TiO2(101) Surfaces: The Effect of Subsurface Defects on Water Adsorption at Near-Ambient Pressures, J. Phys. Chem. C, 119 (2015) 13682-13690.

[46] J.F. Moulder, W.F. Stickle, P.E. Sobol, K.D. Bomben, Handbook of X-ray photoelectron spectroscopy, A Reference Book of Standard Spectra for Identification and Interpretation of XPS Data, Perkin-Elmer Corporation, Eden Prairie, Minnesota, 1992.

[47] G.G. Fuentes, E. Elizalde, F. Yubero, J.M. Sanz, Electron inelastic mean free path for $\mathrm{Ti}, \mathrm{TiC}$, TiN and $\mathrm{TiO}_{2}$ as determined by quantitative reflection electron energy-loss spectroscopy, Surf. Interface Anal., 33 (2002) 230-237.

Figure 1: Development of the open circuit potential (E $\mathrm{E}_{\mathrm{OCP}}$ ) during immersion of $\mathrm{Ti}$ felt in $35 \% \mathrm{HCl}$ at $54{ }^{\circ} \mathrm{C}$

Figure 2: SEM picture of the Ti felt before (A) and after etching (B) in $35 \% \mathrm{HCl}$ at $54{ }^{\circ} \mathrm{C}$ for $300 \mathrm{~s}$

Figure 3: XRD spectra of the Ti felt before (pristine) and after etching (etched) in $35 \% \mathrm{HCl}$ at $54{ }^{\circ} \mathrm{C}$ for $300 \mathrm{~s}$. The diffraction peak positions of individual phases are shown in the upper part of the plots

Figure 4: Ti 2p XPS spectra of the pristine, etched and etched Ti felt aged for 7 months in air at room temperature. Spectra were normalised to the integral area of unity. Positions of the individual Ti $2 p$ lines are indicated by vertical dotted lines and assigned in the figure

Figure 5: Distribution of oxidation states of $\mathrm{Ti}$ in the $\mathrm{Ti}$ felts after various treatments determined from the XPS spectra presented in Figure 4

Figure 6: O 1s XPS spectra of the pristine, etched and etched Ti felt aged for 7 months in air at room temperature. Spectra were normalised to the integral area of unity

Figure 7: (A) Load curves of PEM WE cell operated at $60{ }^{\circ} \mathrm{C}$ (anode loading of $0.75 \mathrm{mg}_{\text {Ir }} \mathrm{cm}^{-2}$, cathode loading of $1 \mathrm{mg}_{\mathrm{Pt}} \mathrm{cm}^{-2}$ ). Duration of the cell operation is given in the figure inset. Multiple points visible for the same voltage are result of development/stabilisation of the current density during constant voltage step. (B) Examples of the obtained electrochemical impedance spectra obtained in the case of PEM water electrolyser with the pristine and the etched Ti felts, spectra obtained at cell voltage of $1.6 \mathrm{~V}$ at the beginning of the PEM WE operation. (C) Overall ohmic resistance $\mathrm{R}_{\mathrm{ohm}}$ of the PEM water electrolysis cells (containing pristine and etched Ti felt) determined by electrochemical impedance spectroscopy. Multiple points visible for the same voltage are present since ohmic resistance values obtained at all measured cell voltages are presented in the figure 
Figure 8: (A) XRD spectra of the etched Ti felt after 108 hours of PEM WE operation. The diffraction peak positions for individual phases are shown in the upper part of the plots. (B) Ti 2p XPS spectra of the etched Ti felt after 108 hours of PEM WE operation. The positions of the dominant Ti $2 p$ lines are indicated by vertical dotted lines and are assigned in the figure 